
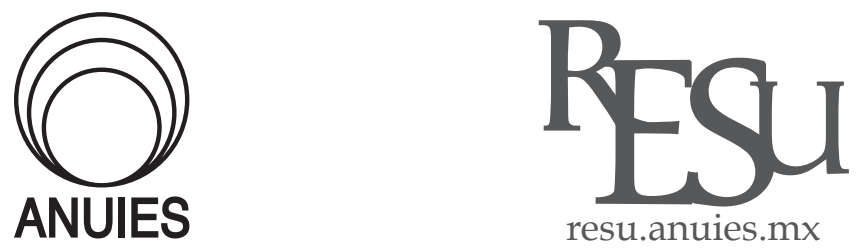

EDITORIAL

\title{
Democratizar la universidad
}

\author{
Imanol Ordorika
}

$\mathrm{B}_{\mathrm{n}}^{\mathrm{u}}$ uena parte de las universidades públicas y autónomas de nuestro país son instituciones autoritarias en las que no predomina la participación de las comunidades, la rendición de cuentas, el acceso a la información y la transparencia. La Universidad Nacional Autónoma de México (UNAM) ha sido referente en la organización del gobierno y la gestión de varias de ellas. Por esta razón y en el contexto actual de grandes cambios nacionales y movilizaciones estudiantiles, es conveniente reiterar que la UNAM no es una institución democrática.

A pesar de ello, a las exigencias de democratización que durante los meses de septiembre y octubre de 2018 plantearon una vez más los estudiantes, se respondió con una caracterización discutible, argumentando que la UNAM es un espacio plenamente democrático. ${ }^{1}$ Es necesario explicar con cuidado por qué esta caracterización es equivocada y plantear que la democratización es posible y necesaria. Las demandas sociales a favor de la democratización en diversos ámbitos e instituciones, así como las expresiones estudiantiles de 2018 y el ambiente de cambio que se vive hoy en México, abren oportunidades inéditas para imaginar y construir un modelo democrático universitario.

\section{Fundamentos de la antidemocracia universitaria}

En la exposición de motivos de la Ley Orgánica de la UnAM de 1945, Alfonso Caso (1944) enunció tres principios en los que aún descansa la actual estructura de gobierno de la

\footnotetext{
${ }^{1}$ Ver por ejemplo Dr. Enrique Graue Wiechers, Respuesta al pliego petitorio, 10 de octubre de 2018 (Gaceta UNAM, 11 octubre 2018, http:/ / www.gaceta.unam.mx/respuesta-a-pliego-petitorio/ consultado el 30 de octubre de 2018) y Pedro Salazar, "La democracia universitaria”, El Financiero, 17 de octubre de 2018 (http://www.elfinanciero.com.mx/opinion/pedro-salazar/la-democracia-universitaria, consultado el 30 de octubre de 2018).
} 
Universidad: a) el carácter de corporación pública nacional; b) sus fines esencialmente técnicos (impartir la educación superior y organizar la investigación científica, así como extender los beneficios de la cultura), subordinados a un fin ético: formar profesionistas y técnicos útiles a la sociedad; y c) los fines de esta comunidad de cultura (enseñar y aprender) no pueden estar nunca en contradicción, por lo que la Universidad debe tener "una sana y racional organización técnica".

De esa concepción se derivó un eje rector de la organización universitaria: "la separación de lo político y lo técnico". De forma explícita, Caso señaló que la democracia era indispensable para la organización del Estado, dada la existencia de opiniones, fines e intereses divergentes en la sociedad; en la Universidad, en cambio, "la situación es totalmente diferente", dado que no existen y no tienen porque existir intereses antagónicos. Con base en tal argumentación, se justificó la existencia de dos tipos de autoridades: las técnicas y legislativas y las ejecutivas. Con el fin de que estas últimas no se transformaran en políticas, su nombramiento estaría "encomendado a personas de autoridad científica y moral indiscutible, y totalmente alejadas de los intereses inmediatos de los profesores y estudiantes universitarios": la Junta de Gobierno. Para el caso de las autoridades "técnicas y legislativas" argumentó que la Ley Orgánica "admite la colaboración de todos y una organización democrática que fomente, entre los estudiantes y los profesores, su sentido de responsabilidad y su participación en la vida misma de la casa de estudios, en lo que tiene de esencial, que es el cumplimiento de sus actividades técnicas, y en la expedición de sus reglamentos y demás actos legislativos" (Caso, 1944).

La Ley Orgánica actual se discutió en un Consejo Constituyente Universitario en 1944. En ese evento muchos universitarios - entre los que destacaron el Dr. Mario de la Cueva (Ramírez, 1979) y la totalidad de los representantes estudiantiles al Constituyente, que renunciaron a este cuerpo en protesta por el contenido de la propuesta de Ley - cuestionaron estos "principios" y algunos de sus derivados: el carácter de los órganos técnicos, la representación escasa de estudiantes, la falta de democracia y, principalmente, la existencia de la Junta de Gobierno (Ordorika, 2006 pp. 93-94).

El debate sobre la democracia universitaria ha continuado por décadas. El cuestionamiento a la normatividad vigente, y las formas de gobierno que sanciona, se ha hecho patente en el nombramiento de varios directores y rectores, como el de Ignacio Chávez en 1961; en los procesos de democratización de escuelas y facultades que tuvieron lugar en los años setenta y ochenta; en los movimientos estudiantiles del CEU de 1966, del CEU en 1986, el CGH en 1999 y el que tiene lugar en estos días; así como en el Congreso Universitario de 
1990. A partir de los movimientos sindicales de los años setenta y ochenta, del movimiento del Consejo Estudiantil Universitario, en 1986, y del Congreso Universitario de 1990, son muy pocos los que aun sostienen la idea de que en la UNAM no coexisten opiniones, fines, proyectos e intereses diferentes que, en ocasiones, llegan a ser incluso antagónicos (Mendoza Rojas, 2001).

A lo largo de estos años, sin embargo, las transformaciones de las normas y formas de gobierno vigentes han sido menores. Los grupos que han detentado el poder universitario, en el ámbito general, o en el de subsistemas o entidades académicas, defienden el orden vigente argumentando que éste ha garantizado un gobierno participativo, representativo y plural, una auténtica democracia universitaria. En los últimos días en defensa de esta postura se han reeditado recuentos históricos que buscan magnificar las virtudes de la Ley Orgánica de 1945 y la estructura que sustenta, de cara otras formas de organización de la Universidad, establecidas en las leyes de 1929 y de 1933 a las que se ha caracterizado, al margen del contexto en que existieron, como políticas y conducentes a la inestabilidad y el desequilibrio de la institución.

En estas discusiones no se ha tomado en cuenta el hecho de que, en distintos países del mundo, algunos sistemas universitarios y universidades utilizan formas diversas de sufragio (de estudiantes, profesores e incluso de trabajadores) para la elección de autoridades centrales (rectores, presidentes o cancilleres) y locales (decanos y directores). Incluso en algunos países como España e Italia, la ley obliga a las universidades a la adopción de procedimientos democráticos para la elección de los cargos principales (Ordorika, 2015). También se han ridiculizado y rechazado otras formas de gestión de universidades públicas en el país, intentando señalar, de manera equivocada, que el sistema imperante en la UNAM es el más generalizado cuando, de hecho, la elección de Rector por medio de votaciones en los consejos universitarios es la forma más común en las universidades autónomas del país. Finalmente se hacen recuentos comparativos de conflictos y caídas de rectores en distintas épocas, tratando de presentar a la normatividad y las estructuras de gobierno actuales como elementos de estabilidad y permanencia, minimizando su incapacidad para prevenir o resolver conflictos como los de 1986, 1999 y 2018, así como su carácter estático, resistente al cambio, anacrónico y conservador de un statu quo oligárquico y autoritario.

Anacronismo normativo y organizativo

Considerar la Ley Orgánica, el Estatuto y las estructuras de gobierno vigentes como anacrónicas no es sólo un calificativo. Éstos fueron discutidos y aprobados en el contexto defensivo de la segunda guerra mundial y para prevenir que los grupos católicos conservadores y filo fascistas se apoderaran del control de la Universidad. Correspondían además a una institución 
muy distinta de la actual. En 1945, la UNAM contaba con cerca de 21 mil estudiantes, la mitad de ellos ubicados en la Escuela Nacional Preparatoria; con 3,400 profesores, prácticamente todos de asignatura; y con aproximadamente 3 mil trabajadores manuales y administrativos, que no estaban sindicalizados (Ordorika, 2006). Hoy la UnAM tiene 350 mil estudiantes de bachillerato, licenciatura y posgrado; más de 40 mil académicos, de los que 12,400 son de tiempo completo; así como 26,400 trabajadores de base y 3,800 de confianza (UNAM, 2018). Buena parte de los académicos y trabajadores están afiliados al AAPAUNAM y el STUNAM, respectivamente. La Universidad Nacional es hoy casi 15 veces más grande y mucho más compleja que aquella de 1945.

\section{Oligarquía académica}

La Ley Orgánica y el Estatuto General de la UNAM concentran el poder y la capacidad de decisión en las autoridades ejecutivas (Rector y directores) por encima de las autoridades técnicas y legislativas (consejos técnicos y Consejo Universitario). En primer lugar, el poder de los primeros deriva directamente de la Junta de Gobierno, que en la jerarquización de autoridades que se establecen en la Ley Orgánica y en el Estatuto se encuentra por encima del Consejo Universitario. En estos dos textos normativos, el Consejo Universitario se encuentra por encima del Rector. En los hechos, sin embargo, la figura del Rector tiene preminencia sobre el Consejo como cuerpo, y una influencia decisiva en la orientación de sus discusiones y el sentido de sus acuerdos. En primer lugar, la rectoría controla la agenda del Consejo. Además, para cualquier observador resulta evidente que en la gran mayoría de los casos este cuerpo colegiado aprueba las iniciativas del Rector. Destacan, en particular, las propuestas oficiales para integrantes de la Junta de Gobierno, la formulación del presupuesto y la cuenta anual de la UNAM, que han sido siempre aprobadas por el Consejo, de 1945 a la fecha, sin excepción.

En el caso de las escuelas y facultades, los directores aparecen como autoridades superiores a los consejos técnicos. La Ley Orgánica establece que éstos "serán órganos necesarios de consulta en los casos que señale el Estatuto". La Ley Orgánica otorga a los consejos sólo una atribución decisoria y ésta es de la máxima relevancia: "aprobar las ternas que formula el Rector para el nombramiento de directores por parte de la Junta de Gobierno". Sin embargo, esta capacidad es prácticamente anulada por el Estatuto General que establece que los consejos sólo podrán impugnar las ternas, "total o parcialmente, en el caso de que los candidatos no satisfagan los requisitos" de nacionalidad, edad, grado y antigüedad. Las demás atribuciones fijadas en 
el Estatuto son las de formular, estudiar y dictaminar proyectos o iniciativas (del Rector, el Consejo Universitario, el director, los profesores y los alumnos), estudiar planes y programas de estudio, hacer observaciones (por mayoría de dos tercios) a las resoluciones del Consejo Universitario o del Rector que tengan carácter técnico o legislativo y afecten a la facultad o escuela. La atribución más importante de estos consejos es la de dictaminar, en los términos que establece el Estatuto del Personal Académico, los nombramientos y promociones del personal académico.

Las decisiones finales sobre el ejercicio de los recursos financieros recaen exclusivamente en el Rector, a nivel general, y en el de los directores en los institutos, centros, escuelas, facultades. Mas allá de la aprobación inicial del presupuesto general y final de la cuenta anual, la normatividad de la UNAM no establece mecanismos de supervisión y aprobación del ejercicio del gasto por parte de órganos colegiados con representación de estudiantes y profesores. Solamente el Patronato universitario, nombrado por la Junta de Gobierno, que es responsable, en términos generales, de administrar el patrimonio universitario, de formular - con el Rector y el Consejo Universitario - el presupuesto anual y presentar la cuenta anual.

En la interacción con los estudiantes movilizados en 2018, las autoridades han argumentado que en la UNAM se practica una democracia meritocrática (dos términos contradictorios) o una llamada "epistémica". Para argumentar la existencia de esta "democracia" peculiar se hace un recuento de más de 700 "cuerpos colegiados" que incluyen desde las comisiones dictaminadoras hasta las de bibliotecas y cómputo. En la Ley Orgánica no se menciona la existencia de cuerpos colegiados y sólo consigna una comisión, la de Presupuesto del Consejo Universitario. El Estatuto habla de cuerpos (sin la denominación de colegiados) en referencia al Consejo Universitario y los consejos técnicos; denomina cuerpos colegiados a los Consejos Académicos de Área, "órganos de carácter propositivo, de planeación, evaluación y decisión académicas"; establece el Consejo Académico de Posgrado y menciona a otros cuerpos académicos que no quedan especificados. También precisa la existencia de comisiones permanentes y especiales del Consejo Universitario, y señala la creación de comisiones dictaminadoras, "órganos auxiliares de los respectivos consejos técnicos" para el ingreso y la promoción del personal académico.

La existencia de estos cuerpos y la gestión colectiva de procesos universitarios generales o locales no es necesariamente democrática. Un ejemplo claro es el caso de las comisiones dictaminadoras en las que participan académicos en la administración del ingreso y la promoción de sus colegas. Los integrantes de estas comisiones auxiliares se rigen conforme a reglas estable- 
cidas de antemano. El hecho democrático sería que los académicos participaran en el establecimiento mismo de las reglas y criterios de evaluación, cosa que no ocurre.

\section{Meritocracia y representación limitada}

Desde los orígenes de la Universidad Nacional en 1910, la integración de estudiantes a los órganos de decisión generó intensas polémicas. La idea de cogobierno de estudiantes y profesores, proveniente de la Reforma de Córdoba, en 1918, influyó en la constitución paritaria de las academias de estudiantes y profesores establecidas en las leyes orgánicas de 1929 y 1933. El conflicto entre los grupos afines al régimen de Ávila Camacho y los grupos católicos atrincherados en la Universidad en 1944 dio lugar a la estructura de gobierno que hemos mencionado y en la que la representación de estudiantes ante los consejos técnicos se redujo al mínimo (La Ley Orgánica establece sólo dos estudiantes en cada consejo), mientras que la de profesores quedó indeterminada.

Llama la atención la conformación actual de consejos como el de la Facultad de Medicina con 74 profesores por cuatro estudiantes; 46 a cuatro en Veterinaria y 46 a ocho en la Escuela Nacional Preparatoria; 30 a 4 en las facultades de Derecho, Ingeniería y Psicología; y 40 a 10 en el Colegio de Ciencias y Humanidades. En contraste sólo las facultades de Ciencias y de Ciencias Políticas y Sociales tienen consejos paritarios. En suma, 645 consejeros técnicos representan a 41 mil profesores (157 representantes por cada 10 mil), mientras que 136 representan a 284 mil estudiantes (4.8 por cada 10 mil).

En el Consejo Universitario (modificado en 2014 para ampliar la representación numérica) la situación es similar, aunque en este caso también el personal académico tiene una representación insuficiente de cara a los directores nombrados por la Junta de Gobierno. El cuerpo conformado por el Rector y los directores de escuelas, facultades e institutos está todo en el Consejo y constituye el $21 \%$ de este cuerpo. Los 2,106 investigadores de institutos cuentan con 66 consejeros, 31 por cada mil; 450 investigadores de centros tienen 4 representantes, casi 9 por cada mil; 1,880 técnicos académicos con 10, 5.3 por cada mil. Hay además 6,502 profesores de bachillerato con 12 consejeros, 1.8 por cada mil; y 34,566 profesores de escuelas y facultades con 58 representantes, 1.7 por cada mil. Finalmente, 30 mil estudiantes de posgrado cuentan con 12 consejeros ( 0.4 por cada mil); 171 mil estudiantes de escuelas y facultades tienen con 56 (0.3 por cada mil); y a 111 mil estudiantes de bachillerato los representan 16 (0.1 por cada mil). Esta composición del Consejo explica, en 
buena medida, la subordinación al Rector en turno, a través de los consejeros directores cuyos recursos financieros, apoyos en infraestructura y plazas académicas, así como sus posibilidades de repetir en el puesto, dependen directamente del "jefe nato" de la Universidad. Incluso para aquellos que sostienen la idea de una representación ponderada o una jerarquización meritocrática, con la condición antes descrita, resulta prácticamente imposible sostener que en la UNAM impera un sistema de participación democrática en la toma de decisiones.

\section{Designación de autoridades}

La designación de autoridades unipersonales en la UNAM tampoco es democrática. El propósito explícito de la creación de la Junta de Gobierno con la Ley de 1945 era ubicar estas decisiones por encima y al margen de los estudiantes y académicos universitarios. Ya hemos señalado que en el nombramiento de integrantes de la Junta siempre han sido preponderantes las propuestas promovidas por la rectoría. En muchos casos están precedidas por presiones y negociaciones entre grupos de interés que ocurren completamente al margen del conjunto de los universitarios. En los 73 años de vigencia de la Ley, la composición de la Junta ha sido muy poco diversa, dominada por médicos, abogados, ingenieros, químicos y contadores, por hombres (90\%) y por posturas conservadoras (Ordorika, 2006).

Los mecanismos de la Junta no son de ninguna manera democráticos. Los integrantes de la Junta no actúan en representación de estudiantes o de académicos. Sus decisiones han respondido, históricamente, a presiones externas (del gobierno o de grupos de interés) e internas (poderes universitarios). Sus deliberaciones son cerradas. La interacción con las comunidades interesadas está enmarcada en la práctica de la auscultación. En contra de cualquier justificación de carácter meritocrática, sus decisiones no implican la primacía del mérito académico. Tampoco reflejan las preferencias mayoritarias de estudiantes o académicos. En las designaciones hechas por la Junta de Gobierno no hay participación real, transparencia ni rendición de cuentas, de cara a los universitarios.

\section{Autoritarismo presidencialista}

En la UNAM se han reproducido los rasgos más característicos de los regímenes políticos del país: el autoritarismo y su forma mexicana, el presiden- 
cialismo. Son evidentes varias características constitutivas del autoritarismo, según la definición clásica de la ciencia política (Linz, 1975). En la dimensión ideológica, en la Universidad se mantienen tres referentes identitarios de diferente orden e interpretación laxa: la autonomía, la libertad de cátedra y la meritocracia. En segundo lugar, los mecanismos de nombramiento de autoridades han anulado cualquier posibilidad de competencia real entre visiones alternativas de Universidad. En consecuencia, ha prevalecido una continuidad sorprendente de los grupos dominantes, principalmente el de los médicos, que desde 1945 ha tenido siete rectores, los abogados con tres y, en menor medida, los ingenieros con dos. Además, la participación social (de académicos y estudiantes) es escasa, y cuando existe se enfrenta a un fuerte control centralizado. Finalmente, existe baja representatividad y atribuciones limitadas en órganos colegiados, y preponderancia de las autoridades ejecutivas o unipersonales (Rector y directores).

A imagen y semejanza del sistema político autoritario que ha prevalecido en México, las autoridades unipersonales - principalmente el Rector, aunque también a nivel local, los directores - tienen un margen de actuación y ejercen poderes más allá de los establecidos en las normas. Las atribuciones meta normativas, rasgo esencial del presidencialismo mexicano (Carpizo, 1978), otorgan a estas autoridades capacidad de decisión muy por encima de las autoridades colectivas (Consejo Universitario y consejos técnicos) que, en la mayoría de los casos, se encuentran subordinados y bajo el control de las autoridades ejecutivas.

\section{Reflexiones finales}

A partir de esta descripción somera, sostenemos una vez más que la Universidad Nacional Autónoma de México no es una institución democrática que garantice una participación, directa o indirecta, de académicos y estudiantes en la toma de decisiones y en el nombramiento de autoridades. Apenas cumple con la normatividad y los requisitos más básicos de transparencia y rendición de cuentas, pues éstos no se permiten un escrutinio real del ejercicio del gasto, los procesos de toma de decisiones y del nombramiento de autoridades, que en nombre de toda una "comunidad" hacen la Junta de Gobierno y el Rector.

En los últimos 70 años, México ha sufrido fuertes transformaciones, entre ellas resaltan los avances en materia de transparencia, acceso a la información y rendición de cuentas. Aun más significativos son los cambios en las reglas y en los procesos de elección de gobernantes. La UNAM, sin embar- 
go, se encuentra completamente rezagada respecto a estos cambios que han ocurrido en el país. Una y otra vez, los grupos dominantes en la institución se han opuesto a las propuestas de transformación democrática aduciendo una condición particular y casi única de la institución universitaria, su carácter meritocrático, la necesaria despolitización en favor de una estabilidad mitificada, y últimamente una esencia democrática difícil de sostener. En el recuento oficial se hace caso omiso de la incapacidad de la Universidad para dar cauce a demandas legítimas de académicos, estudiantes y trabajadores que se han traducido, desde los años setenta por lo menos, en conflictos sindicales (Woldenberg, 1988) y grandes confrontaciones como las de 1986-1987 (Bartra, 2003) y 1999-2000 (Rosas, 2001).

El movimiento estudiantil de 2018 planteó cuatro grandes ámbitos de cambio profundo para la UNAM: los temas de seguridad, de equidad de genero, de democratización y de ampliación de la matrícula. De un modo u otro todos se articulan en torno a la exigencia de democratizar la Universidad, demanda en la que convergen aspiraciones de cambio de muchas generaciones de universitarios.

La Universidad Nacional está frente a una nueva oportunidad para hacer posible esta aspiración, partiendo de la creatividad, la energía y el potencial de cambio que aportan una vez más los estudiantes. En esta ocasión no se puede dejar pasar la oportunidad de colocar a la Universidad Nacional Autónoma de México a la altura de los tiempos que hoy se viven. Las universidades publicas del país tenemos frente a nosotros el reto de transformar el paradigma universitario del apoliticismo, instaurado con la Ley Orgánica de 1945, y dar paso a formas de gobierno y de organización modernas y participativas, en sintonía con la aspiración nacional de democracia, rendición de cuentas, acceso a la información y transparencia. La Universidad Nacional deberá estar al frente de este proceso de cambio, y el riesgo de no hacerlo es quedar atrapada en el pasado y seguir al margen de los procesos de cambio social en nuestro país.

\section{Referencias}

Bartra, Roger (2003). “El espíritu autoritario y la raza crítica." En Oficio Mexicano, editado por R. Bartra. Pp. 59-78. México: Conaculta.

Carpizo, Jorge (1978). El presidencialismo mexicano. México: Siglo Veintiuno Editores.

Caso, Alfonso (1944). Exposición de motivos. Presentación ante el Consejo Constituyente Universitario del proyecto de Ley Orgánica. En http://www.dgelu.unam. $\mathrm{mx} / \mathrm{m} 2-1 . h t m l$, consultado el 20 de octubre de 2018. 
Linz, Juan (1975). “Totalitarian and Authoritarian Regimes." En Handbook of Political Science, editado por F. Greenstein y N. Polsby. Pp. 175-411. Reading, Mass.: Addison Wesley.

Mendoza Rojas, Javier (2001). Los conflictos de la UNAM en el siglo Xx. México, D.F.: Centro de Estudios sobre la Universidad Plaza y Valdés.

Ordorika, Imanol (2006). La disputa por el campus: poder, política y autonomía en la UNAM. Plaza y Valdés/SES-UNAM.

Ordorika, Imanol (2015). "Elección de rector: panorama internacional." Revista de la educación superior, 44 (175): 7-18.

Ramírez, Carlos (24 de febrero de 1979). "Mario de la Cueva: La unAM, invadida por el priísmo y traicionada por el Estado (entrevista)". Proceso, 121.

Rosas, María (2001). Plebeyas batallas : la huelga en la Universidad. México, D. F.: Ediciones Era.

unAm (2018). Agenda estadística 2018. México: Universidad Nacional Autónoma de México.

Woldenberg, José (1988). Historia documental del SPAUNAM. México: Universidad Nacional Autónoma de México Facultad de Ciencias Políticas y Sociales y Facultad de Economía : Ediciones de Cultura Popular. 